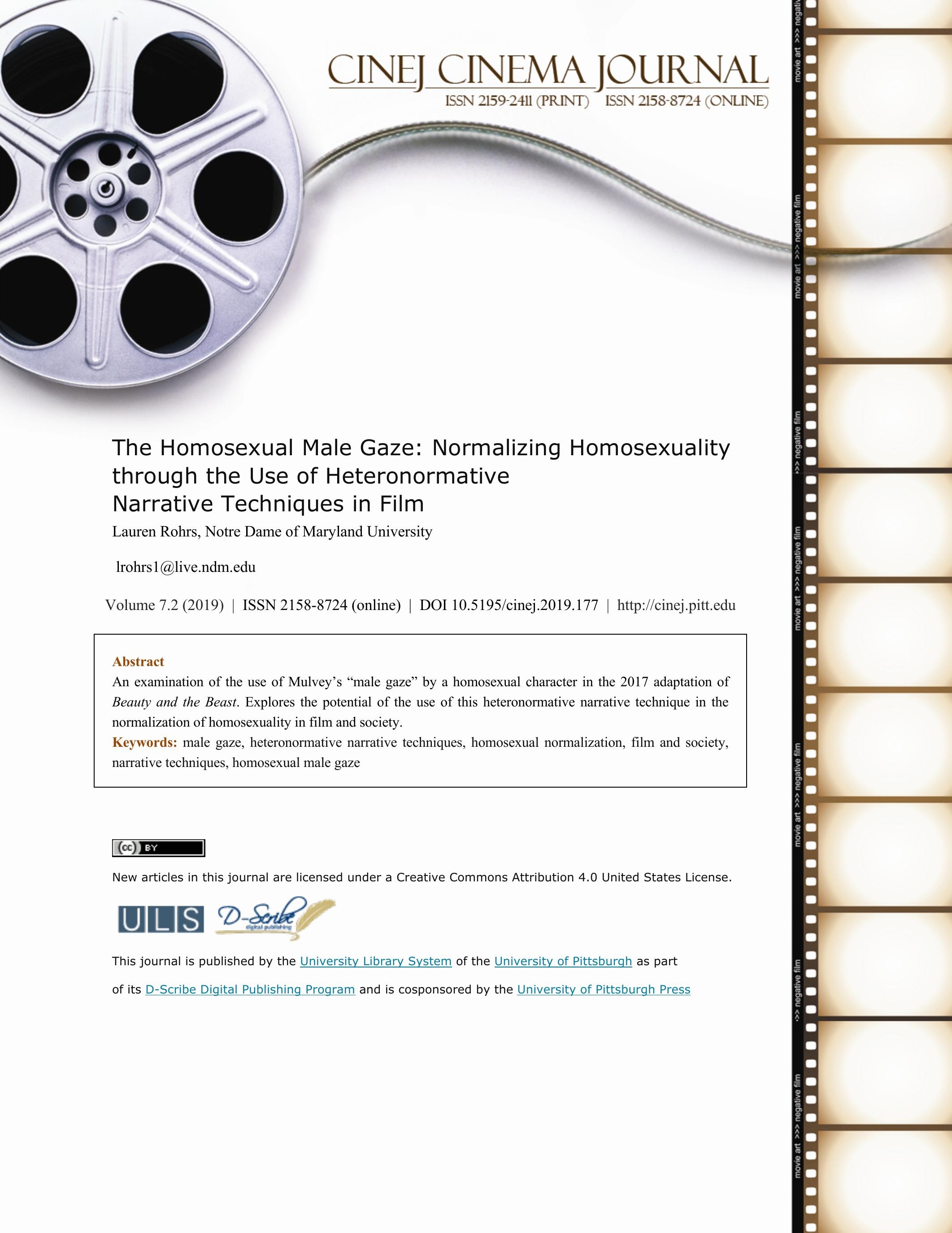




\section{The Homosexual Male Gaze: Normalizing Homosexuality through the Use of Heteronormative Narrative Techniques in Film}

\section{Lauren Rohrs}

In recent months, the film company Disney came under scrutiny as it was announced that

a character in the 2017 film Beauty and the Beast, LeFou, was being portrayed as homosexual

(Izadi). As a result, the film has been boycotted and banned, yet while watching the film there is

no overt "gay scene", meaning a kiss (or more) between two characters of the same sex, that could

be seen as a point of contention for homophobic viewers; what then makes this character so

controversial? The sexuality of the character in question is made clear to the audience almost

exclusively through his use of "the look" and the male gaze when looking towards his love interest,

Gaston. The sexual tension, attraction, and desire experienced by LeFou are palpable and clear to

the audience, despite a lack of sexual advancement, declaration of love, or other overt references

to the character's sexuality. While in her essay "Visual Pleasure and Narrative Cinema" Mulvey

was strictly describing women as the objects of "the male gaze", her statement that the way

characters have been "displayed has functioned on two levels: as erotic object for the characters

within the screen story, and as erotic object for the spectator within the auditorium, with a shifting

tension between the looks on either side of the screen" (Mulvey 270) can be, in this case, applied

to a male character who is the object of the male gaze. In Beauty and the Beast, the love interest

CINEJ Cinema Journal: The Homosexual Male Gaze

Volume 7.2 (2019) | ISSN 2158-8724 (online) | DOI 10.5195/cinej.2019.177| http://cinej.pitt.edu 
of the gay character becomes the object of the male gaze and undergoes a similar transformation;

his desirability is largely communicated to the audience through the use of the male gaze, while the sexual orientation of "the looker" is expressed in a similar fashion to the traditional presentation of attraction from heterosexual male characters - by observing another man as an "erotic object", the sexual orientation of this character is communicated without the need to announce to the audience that the character is homosexual or to exaggerate the character's behavior to match a heterosexual audience's stereotype of what it means to "act gay".

Through an examination of the 2017 film adaptation of Beauty and the Beast, Mulvey's theoretical work on the male gaze, and Dyer's criticism of the portrayal of homosexual men in media, I will argue that the use of the male gaze by a homosexual character serves as a powerful narrative tool, sexual identifier, and normalization tool that can indicate the sexuality of the homosexual character without exaggeration and in such a way that helps to normalize homosexual relationships through the use of widely accepted and normalized indicators of heterosexual attraction in film.

\section{Beauty and the Beast and Homosexuality}

The example of homosexual male gaze utilized in this paper is that of the 2017 live action film adaptation of Disney's Beauty and the Beast. The film became a topic of controversy when it 
was announced that one of the film's characters, LeFou, would appear as Disney's first openly homosexual character. His love interest, Gaston, remained heterosexual, and the film lacked a definitive moment in which LeFou's sexuality was explicitly stated; apart from a brief moment in the film's final scene in which LeFou is accidentally "handed" a male dance partner in a ballroom scene, the entirety of his storyline as a gay man relies on a series of "looks" that he directs towards Gaston. These looks, which are prevalent throughout the first half of the movie, dwindle and eventually cease to occur towards the end of the movie, when the message of Gaston's attractiveness turns to one of his villainy. The use of the male gaze as a signifier of LeFou's sexual orientation (as opposed to a verbal declaration of his sexuality, physical romantic contact between his character and Gaston, or an exaggerated flamboyance in his personality) presents homosexuality in a similar fashion as heterosexuality has been traditionally portrayed in film. Although this film was met with hostility because of this character's sexual orientation, the majority of this negative backlash occurred before the film's release, indicating that any anger incited by this character's sexual orientation came from those who learned of his sexual orientation through news media sources, and not through an experience with the character interactions within the film. Using this film as an example, an examination of the homosexual male gaze as a sexual identifier, narrative tool, and normalization tool in the context of existing film theories can be 
applied and examined in the context of the interactions between the characters of LeFou and

Gaston.

\section{Mulvey's Male Gaze}

Mulvey's theory on the male gaze in film can be largely summarized in her statement "in a world ordered by sexual imbalance, pleasure in looking has been split between active/male and passive/female" (Mulvey 270). Mulvey's theory on male-female interactions in film "takes as starting point the way film reflects, reveals, and even plays on the straight, socially established interpretation of sexual difference which controls images, erotic ways of looking and spectacle" (Mulvey 267), establishing the earliest examination of the subliminal ways in which film reflects and feeds into patriarchal society through the use of what Mulvey defines as "the male gaze", a filming technique that plays into scopophilia and allows viewers to experience a film (and its female characters) through the perspective of the leading male character. Mulvey criticizes the use of this film technique in response to the idea of scopophilia, which she defines as "taking other people as objects, subjecting them to a controlling or curious gaze" (Mulvey 269); for Mulvey, "psychoanalytic theory is thus appropriated here as a political weapon, demonstrating the way the unconscious of patriarchal society has structured film form" (Mulvey 267). For Mulvey, the objectification of women in film feeds into patriarchal norms and views of women, however she 
also views film as a potentially valuable psychoanalytic model, stating "as an advanced representation system, the cinema poses questions of the ways the unconscious (formed by the dominant order) structures ways of seeing and pleasure in looking" (Mulvey 268). For Mulvey, this tool, which results in the objectification of women for the pleasure of both the male character that presents the point of view as well as for the pleasure of the audience, is the result of the unconscious human structures of pleasure as well as the fodder that feeds into this structure.

Of Mulvey's claims, the most significant to an examination of the homosexual male gaze is her claim that "sexual instinct and identification processes have a meaning within the symbolic order which articulates desire" (270). Through this statement, Mulvey identifies patriarchal film techniques, such as "the look" and the male gaze, as symbolic of sexual instinct and identification; those characters who present the male gaze towards female characters are identified to the audience as heterosexual, with their objects of desire easily identified as the women to whom they direct their gaze. When this technique is applied to a homosexual male character, the same inferences can be drawn from the object of his gaze, identifying him as homosexual based on his gaze towards another $\mathrm{man} / \mathrm{men}$.

Homosexual Male Gaze as a Sexual Identifier in Beauty and the Beast 
Mulvey's claim that "sexual instinct and identification processes have a meaning within the symbolic order which articulates desire" (270) presents a strong argument for the use of the male gaze from a homosexual male character to another male character as a sexual identification tool in film. As Mulvey determines that patriarchal narrative film techniques are symbolic of sexual instinct, sexual identification, and desire, it can be argued that these same tools, when presented from the point of view of a homosexual male character, are capable of identifying the character's sexual orientation, as well as the object of his desire. In the 2017 adaptation of Beauty and the Beast, the use of typically patriarchal narrative tools serve to narrate the sexual identification of the character, LeFou. In the opening scene of the film, the characters LeFou and Gaston are introduced to the viewer as they sit on horseback on a distant field observing their town from a distance. In an almost perfectly mirrored moment in the film, Gaston, who opens the scene by viewing his female object of desire through a telescope (an almost too-perfect parallel to the film Rear Window, highlighted by Mulvey as an example of the male gaze), becomes the object of the homosexual male gaze as his companion, LeFou, gains the position of the possessor of the male gaze, making Gaston the newly highlighted object of desire. The camera shifts from the view from Gaston's telescope to Gaston himself, straddling his horse and serving as the film's early sex symbol. In this scene, the audience is presented with two instances of the male gaze, one which meets viewer expectations as "the norm" and another that introduces the homosexual male gaze 
and the idea of a male character becoming the object of the male gaze. Similar instances of the male gaze occur throughout the opening sequence, as the camera is repeatedly placed from LeFou's perspective as the pair ride into town.

\section{Homosexual Male Gaze as a Narrative Tool in Beauty and the Beast}

The use of the male gaze by LeFou towards Gaston plays two major roles in the narration of the film; indicating LeFou's sexual orientation, and guiding the storyline as the attractiveness of Gaston declines for both the audience and LeFou. In the film, Gaston is originally presented as a brainless but hopelessly in love young veteran; though hardly perfect, he is intended to be viewed as desirable by the audience, as the interactions between himself and other characters relies heavily on the understanding that he is a beloved member of the community. As a remake, the 2017 version of Beauty and the Beast faced a potentially difficult narrative dilemma; since the majority of the audience would be familiar with Gaston's villainy, presenting him as a desirable character (and thus setting him up for his decline into undoubtable villainy) would require a creative representation of his character. By making Gaston the object of the male gaze through the view of LeFou, Disney was able to reestablish Gaston as an object of desire; conversely, as the film progresses and Gaston descends into villainy, the presence of the male gaze decreases and 
eventually ceases, removing any indicators that Gaston could be viewed as desirable. This use of the male gaze in Beauty and the Beast is in line with Mulvey's observation about female characters, as she observes "traditionally, the woman displayed has functioned on two levels: as erotic object for the characters within the screen story, and as erotic object for the spectator within the auditorium" (Mulvey 270). The use of the homosexual male gaze in the 2017 adaptation of Beauty and the Beast serves a similar role, presenting not only LeFou's view of Gaston as an "erotic object" but also establishing his erotic nature for the audience. The desire of LeFou for Gaston also works within the context of the theories of Shuckmann, who views the male gaze as "a double structure of desire that establishes a model for the relationship between the male spectator and the image: on the one hand, he desires to possess the image.....and, on the other hand, he desires to be or to become the image" (Shuckmann 673). This analysis of the male gaze in the context of a homosexual character pertains particularly well to the Beauty and the Beast example, as in the original Disney adaptation of the story, LeFou is presented as a hero-worshiper of Gaston (he wishes to be the image) while in the 2017 adaptation of the story, LeFou is seen to both desire to "possess the image" and to "be the image".

The use of the male gaze as a narrative tool to establish LeFou's sexuality is more to the point of this argument; by choosing to establish LeFou's sexuality almost exclusively through "the look" and the male gaze, Disney presented his character as homosexual without falling into the 
trap of exaggeration. The character's storyline, which revolves largely, but not exclusively, around his desire for Gaston and Gaston's approval, requires an establishment of his sexual orientation, making the film's use of the male gaze an important narrative tool for LeFou's character development.

\section{Homosexual Male Gaze as a Normalization Tool}

Apart from the sexual identification and narrative aspects of the homosexual male gaze,

the use of this tool can also (and perhaps most significantly) help to normalize homosexuality through the use of "heteronormative narrative tools" -narrative tools that have been used to indicated heterosexual attraction for decades. By appropriating these tools for homosexual characters, film makers have the power to relay sexual orientation of characters in a way that has been accepted as the norm for heterosexual characters, thereby meeting the audience within its comfort zone and working within a framework familiar to the audience. By thus presenting homosexual attraction on screen, filmmakers are able to escape the use of homosexual stereotypes, as well as overt references to a character's sexuality, while still narrating that the character is nonheterosexual. In this way, homosexual characters can simply exist within a film without their 
sexuality being the main feature of their character; they can be simply characters, as opposed to strictly homosexual characters.

\section{Dyer's Homosexual Stereotyping}

Richard Dyer's opinion on the stereotyped representation of homosexuals in film is unquestionably negative, as he opens his essay Stereotyping stating "gay people, whether activists or not, have resented and attacked the images of homosexuality in films (and the other arts and media) for as long as we have managed to achieve any self-respect...the principle line of attack has been on stereotyping" (Dyer 275). Dyer's essay, which examines the social and political objectives in the stereotyped presentation of homosexual people in media, criticizes the ways in which films stereotype homosexual people and seeks to both understand why these stereotypes are so prevalently reinforced in film, as well as determine the remedy for appropriately identifying homosexual characters without exaggerated stereotyping. For Dyer, "there can be no doubt that most stereotypes of gays in films are demeaning and offensive. Just think of the line-up - the butch dyke and the camp queen, the lesbian vampire and the sadistic queer, the predatory school-mistress and the neurotic faggot, and all the rest. The amount of hatred, fear ridicule and disgust packed into those images is unmistakable" (Dyer 275). Dyer refers to Klapp to define the difference between stereotypes and social types; in his argument, Klapp defines these two concepts as 
“...stereotypes refer to things outside one's social world, whereas social types refer to things with which one is familiar; stereotypes tend to be conceived as functionless or dysfunctional (or, if functional, serving prejudice and conflict mainly), whereas social types serve the structure of society at many points" (Klapp 16). For Dyer, people are condemned to their stereotypes, which are "characteristically fixed, clear-cut, unalterable" and come from external sources, including society, film, and media (Dyer 277). In the context of this paper, Dyer's examination of stereotypes is significant as it highlights stereotyping as a phenomenon enforced from external sources (i.e. societal expectations, film representations, etc.) and as a negative influence on both homosexual individuals (who become objects of ridicule in film) and the heteronormative population (which has its stereotypes about homosexual people confirmed through the stereotyped presentation of homosexual characters in films). These stereotypes are presented and enforced largely through iconography, which uses "a certain set of visual and aural signs which immediately bespeak homosexuality and connote the qualities associated, stereotypically, with it" (Dyer, 278). Dyer points to the desire of the audience (and society in general) to typify individuals, placing them in "simple, vivid, memorable, easily-grasped and widely recognized characterization[s] in which a few traits are foregrounded and changed or 'development' is kept to a minimum" (Dyer, 276). This typifying and stereotyping of homosexual characters not only enforces stereotypes, but also 
generally does not allow for the development of a character that has been typed as homosexual;

this becomes the only significant trait for the character, who's character growth cannot extend beyond the limits set for the "type" to which it is assigned. Although Dyer does not say as much, it is arguable that homosexual characters, within these constraints, cannot be seen as "people" but only as their "type", with character development outside of their "type" becoming impossible as long as the "type" is a primary component of the character's self.

\section{The Homosexual Male Gaze as Unexaggerated Portrayal of Homosexuality in Beauty}

\section{and the Beast}

Although much of LeFou's character centers on his secret sexual orientation, with the majority of his ethical decisions being based on his desire for and subsequent desire to please Gaston, his character, unlike many criticized by Dyer, has depth beyond his sexual orientation and does not fall into any homosexual stereotype; he is neither a "camp queen" nor a "sadistic queer" and he is presented without that exaggerated flamboyance that often signifies a homosexual character's sexual orientation. Beyond his non-stereotypical presentation as a homosexual male character, LeFou also proves capable of developing as a character outside of his sexuality. Throughout the film, as Gaston's actions prove him to be a villain, LeFou's attraction towards Gaston is seen to dwindle, as his use of "the look" and the male gaze reduce until they cease to 
exist. He ultimately finds his own ethical stance, changing his loyalties away from Gaston, and proves capable of standing alone as a character beyond his sexual orientation. Conversely, the final scene of the film, which incited controversy from a homophobic population, maintains LeFou's sexual orientation, establishing that his homosexuality has been, and remains to be, a part of his character; he may have lost his feelings for Gaston, but his sexual orientation is still a significant part of who he is a character.

In addition to (and in conjunction with) these benefits of utilizing the male gaze to establish homosexual orientation, the use of this tool is also significant because of its deeply rooted history in heterosexual narratives; since early Hollywood, the male gaze has served to indicate to audiences the attraction of a male character to his female object of desire; as a long-established narrative tool, the male gaze has become a subconsciously accepted indicator of sexual attraction between a heterosexual couple. As such, the male gaze, when applied to a male character by another male character, remains an accepted, subconscious indicator of sexual attraction; the male gaze is much more subtle than sexual contact between two characters, and yet the same message of sexual attraction is relayed to the viewer. Unlike sexual contact between characters (i.e. a kiss, sexual intimacy, etc.), the male gaze is one-sided (thus requiring only one homosexual character to be utilized) and does not cross into a territory that can "threaten" the views or beliefs of a 
heterosexual viewer. While the opinion of a homophobic individual should not matter for a homosexual individual, if a film (or any other type of media) is attempting to dissolve those "fears" and stereotypes that shape homophobia, it is helpful to the cause to present homosexuality in a normalized but subtle manner. This approach challenges stereotypes about homosexual individuals by presenting non-stereotyped examples of homosexuality, but also works within the comfort zone of an audience that may not be receptive to overt references to homosexuality, granting an opportunity to slowly introduce the idea of homosexuality as a normal form of sexual orientation.

While for Disney a release of this character's sexuality was received negatively in some areas of the country/world, the use of "the look" between non-heterosexual characters has the power to help to normalize non-heterosexuality in society as the message about character sexuality is sent and received in a normalized, un-exaggerated, and "unthreatening" manner; the attraction simply exists and is communicated in the same way that heterosexual attraction has been communicated in film for decades, without the need to place LeFou within a traditional stereotype of homosexual men or to typify him through homosexual iconography through his movements or style of clothing. "The look" is a powerful cinematic tool that is shifting its purpose from presenting a male character's desire for a female character, to normalizing relationships outside of the heterosexual pairings common in films. The use of the male gaze by homosexual characters 
could prove to be a powerful technique in cinematic attempts to present homosexuality in a normalized and non-exaggerated way.

\section{Future Research}

In the future, this research will examine the ethical question of the use of the male gaze and whether the application of this narrative tool to homosexual men is more, less, or equally impermissible to the application of the same tool towards female characters. Although it has been argued that "even though in the gay gaze there is also an objectified one, as it is in the same sex it just represents the gaze which reflects the secret feelings to the other man, but not reduces the other one in an interior position" (Gokcem) I believe that a closer examination of the treatment of homosexual individuals and heterosexual women in film is needed to better understand the standards to which society holds the treatment of these different groups. Although I argue for the benefits of utilizing the male gaze to normalize homosexuality in film, I am hesitant to any claims that homosexual men can ethically be objectified through the male gaze any more than is permissible for heterosexual women. Future research will also examine the use of "the look" or gaze by and between lesbians in film in order to compare the ways in which male and female 
homosexuality are treated in film, and the ways in which homosexual and heterosexual women are treated in film.

\section{Conclusion}

In conclusion, the use of the male gaze by a homosexual male character can prove to be a powerful tool to relay the character's sexual orientation; as a subtle narrative device that indicates the object of a character's desire, the male gaze has the capacity to alert the audience of a character's sexual orientation without the need to revert to stereotypes, iconography, or exaggeration. Although the male gaze has been criticized when used between heterosexual male and female characters, the use of the male gaze in a homosexual context may be a valuable tool in normalizing homosexuality to a heterosexual audience.

\section{Works Cited}

Beauty and the Beast. By Evan Spiliotopoulos Stephen Chbosky. Dir. Bill Condon. Perf. Dan Stevens, Luke Evans, and Josh Gad Emma Watson. Disney. 2017.

Dyer, Richard. "Stereotyping." Durham, Meenakshi G. and Douglas M. Kellner. Media and Cultural Studies Keyworks. John Wiley \& Sons, 2012. 275-283.

Gokcem, Selen. "Transperance Me I Want To Be Visible." Cinej Cinema Journal 1.2 (2012). 
Izadi, Elahe. The Washington Post. 1 March 2017. 1 May 2017. $<$ https://www.washingtonpost.com/news/arts-and-entertainment/wp/2017/03/01/beauty-and-thebeast-to-have-disneys-first-ever-exclusively-gay-moment/>.

Klapp, Orrin E. Heroes, Villains, and Fools. Englewood Cliffs: Prentice-Hall, 1962.

Mulvey, Laura. "Visual Pleasure and Narrative Cinema." Durham, Meenakshi G and Douglas M. Kellner. Media and Cultural Studies Keyworks. John Wiley \& Sons, 2012. 263-274.

Shuckmann, Patrick. "Masculinity, the Male Spectator and the Homoerotic Gaze." Amerikastudien (1998): 671-680. 